\title{
International Molybdenum Association (IMOA) life cycle assessment program and perspectives on the LCA harmonization effort
}

\author{
Anne Landfield Greig ${ }^{1} \cdot$ Sandra Carey $^{2}$
}

Received: 14 May 2015 / Accepted: 24 October 2015 /Published online: 16 December 2015

(C) The Author(s) 2015. This article is published with open access at Springerlink.com

\begin{abstract}
Purpose In 2001, the International Molybdenum Association (IMOA) initiated their life cycle assessment (LCA) program performing cradle-to-gate life cycle inventories (LCIs) of three molybdenum metallurgical products, followed by LCIs of eight molybdenum chemicals and an update to the metallurgical LCIs. From 2012 to 2014, IMOA participated in a multi-metal industry initiative to harmonize the methodological approach to metal-related LCAs. This paper describes some of IMOA's conclusions formed from its program and, coupled with its involvement in the multi-metal initiative, provides some lessons learned.

Methods For this paper, IMOA evaluated the benefits of its LCI program, including its ability to communicate effectively with member companies and stakeholders on the development, use, and application of life cycle data. Likewise, IMOA developed the competence to recognize and provide input on potentially inappropriate use of LCA. IMOA performed a literature review to highlight some of the scientific research using the molybdenum LCI data. IMOA also reviewed the metal industry's guidance document to provide its perspective on it, including similarities, differences, and substantiation of elements of the four topic areas.

Results and discussion The metal industry's guidance document identified four topic areas as essential for alignment with
\end{abstract}

Responsible editor: Martin Baitz

Anne Landfield Greig

anne@ fourelementsllc.com

1 Four Elements Consulting, LLC, 1619 22nd Ave E, Seattle, WA 98112, USA

2 International Molybdenum Association, 454-458 Chiswick High Road, London W4 5TT, UK respect to metal-related LCAs: (1) system boundaries, (2) coproduct modelling, (3) life cycle impact assessment (LCIA), and (4) metals recycling modelling. IMOA is largely in agreement with the approaches described in the document. The paper provides examples of how these have been applied to LCAs on Mo-bearing products as well as examples of how some LCA work can benefit from the guidance document. Conclusions Having taken part in the harmonization effort, IMOA is poised to educate its member companies and stakeholders about some of the challenging issues encountered in LCA and will continue to lead through active industry participation. IMOA supplies its LCI data via a formal request process which enables open dialogue with stakeholders and LCA practitioners while providing IMOA with insights into how its products fit into the broader lifecycle context and facilitating stakeholders' awareness of LCA and metals.

Keywords Molybdenum - Life cycle assessment $\cdot$ Life cycle analysis $\cdot$ LCA $\cdot$ Life cycle inventory $\cdot$ LCI $\cdot$ Harmonization

\section{Introduction to the IMOA life cycle assessment (LCA) Program}

\subsection{Overview of the Molybdenum LCIs}

As an early adopter of metals industry involvement in life cycle assessment (LCA), the International Molybdenum Association (IMOA) has undertaken cradle-to-gate life cycle inventory (LCI) analyses of molybdenum products over the past 15 years that have resulted in a library of high quality global average production data on molybdenum products. In 2001, IMOA completed its first LCIs on three metallurgical molybdenum products: technical grade molybdic oxide (tech oxide) in powder form, tech oxide in briquette form, and 
ferromolybdenum in chip form (Fig. 1). Subsequently, in 2006, IMOA built upon the metallurgical data and added chemical processing to produce LCI data on eight molybdenum chemicals (Fig. 2). (First Environment 2006) The Metallurgical molybdenum LCI study was updated in 2008 to account for an increase in geographical representation, temporal and technological updates of primary (i.e., facility) data, and updated modeling. (Four Elements Consulting, LLC 2008)

The studies adhere to the requirements in the International Standardization Organization (ISO) series of standards on LCA.(ISO 2006a \& 2006b) At the time, the LCIs were first published, the primary metallurgical molybdenum data collected and modeled represented approximately $52 \%$ of total molybdenum production, or $74 \%$ of production excluding China, Mongolia, and Commonwealth of Independent States (CIS, former USSR). The primary processing data collected for the chemical LCIs represented over $90 \%$ of production, excluding China, Mongolia, and CIS.

\subsection{Objectives of the Molybdenum LCIs}

Initially, IMOA's LCA aims were three-fold: supply environmental information to customers, assist member companies to identify areas for process improvement within their own facilities, and measure environmental performance in general within the industry. Study participants have taken lessons learned from the LCI exercise to integrate environmental aspects and impacts into their company-wide environmental and sustainability programs.

With so many market drivers for LCA, such as green building and construction certification programs, EU Product Environmental Footprints and Type III Ecolabels (e.g., Environmental Product Declarations), the demand for LCA studies using high quality upstream data on commodities has steadily increased. IMOA's LCI program has thus evolved into a repository for reliable, high quality molybdenum production data to support cradle-to-grave LCAs involving molybdenum products. IMOA supplies data directly to LCA practitioners or to other organizations producing LCIs on their own products. For example, the International Stainless Steel Forum (ISSF) and World Steel have incorporated metallurgical molybdenum product LCIs into their own LCIs (see ISSF (2015) and worldsteel (2015)). These, in turn, have been embedded by LCA practitioners into hundreds of cradle-to-grave LCAs on stainless steel and steel products.

\section{IMOA's involvement in the harmonization effort}

From 2012 to 2014, IMOA participated in an industry-wide effort to review current LCA practice and experience within the metals and minerals industry, and to develop new guidance on how to adopt a more harmonized approach to LCI and life cycle impact assessment (LCIA) methodologies within the industry. The resulting guidance document (PE 2014a) identifies four topic areas as essential for alignment with respect to metal-related LCAs: (1) system boundaries, (2) coproduct modeling, (3) life cycle impact assessment (LCIA), and (4) metals recycling modeling. The following sections present IMOA's perspective and highlight the issues most relevant to molybdenum.

\subsection{System boundaries}

The cradle-to-gate molybdenum LCIs are intended to be applied in a broader life cycle context. PE (2014a) asserts that
Fig. 1 Metallurgical molybdenum LCI system boundaries: 1 tech oxide in powder form, 2 tech oxide in briquette form, and 3 ferromolybdenum

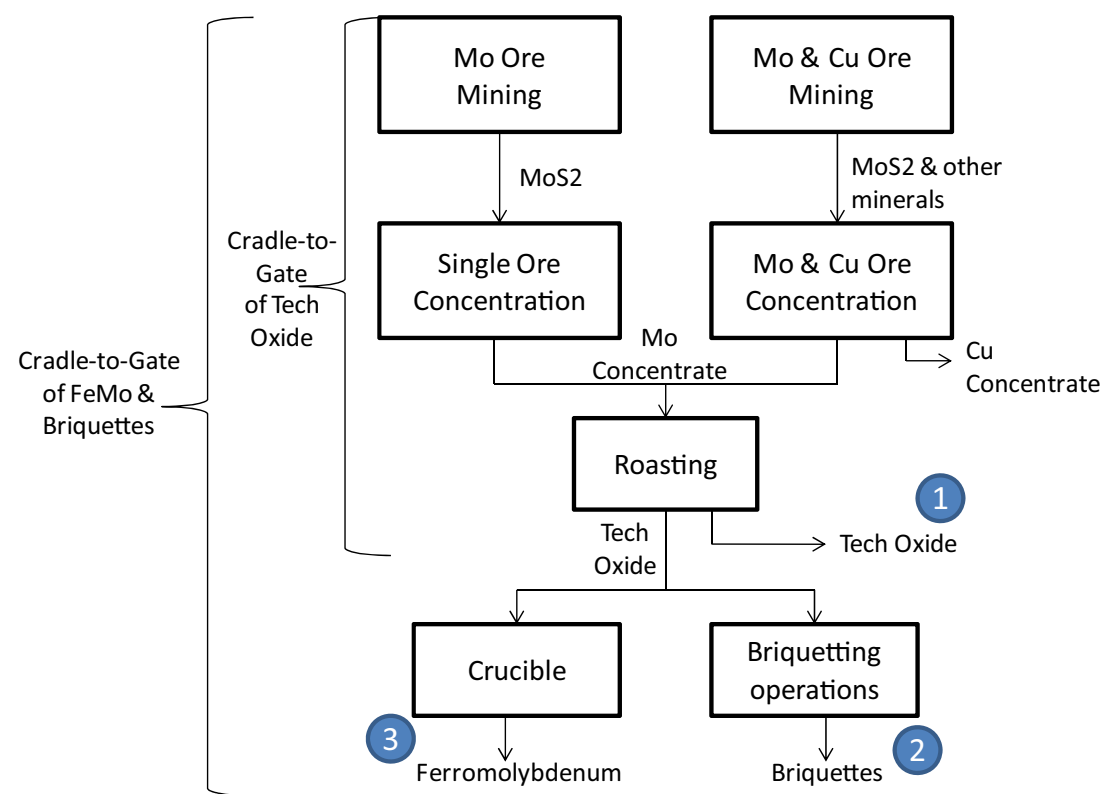






Fig. 2 Molybdenum chemical LCI simplified system boundary, showing upstream production of tech oxide and its input to ammonium dimolybdate production

products should be evaluated on a full life cycle basis, which includes use phase and metal recovery/recycling at end of life, and should be based on a well-defined functional unit that incorporates a product's performance, service life, etc. This ensures a more complete picture of a product's environmental impacts and, by appropriately defining the functional unit, the attributes of the product at use phase (i.e., the reason the product or material is used in the first place) can be justly accounted for.

By way of its formal data request process, IMOA has seen its LCI data applied to cradle-to-grave studies to support both new and conventional applications. For example, as part of an ongoing analysis funded by the US Department of Energy's Bioenergy Technologies Office, Pacific NW National Lab (PNNL) quantified the relative life cycle impacts of catalyst use for a proposed biofuel-upgrading process, which utilizes nickel and molybdenum (NiMo) catalysts or cobalt and molybdenum (CoMo) catalysts. PNNL used molybdenum chemical LCI data to help assess the relative importance of catalyst management scenarios in the context of the overall biofuels upgrading process. The results, which include a comprehensive greenhouse gas (GHG) analysis of the systems, are not yet public.

Lavery et al. (2013) used IMOA's LCI data for molybdenum as an activity enhancing dopant in a sponge nickel catalyst produced by gas atomization. The study evaluated the use of the gas atomization catalyst versus its conventional cast and crush production route, in the reaction of butyraldehyde to butanol. Results found that the benefits of lower energy and emissions during the gas atomization catalyst's use phase outweighed the environmental impacts of the production, manufacturing, and recycling of the materials making up the catalyst. The results specifically identify molybdenum as a contributing factor to the large energy savings during use phase, despite a relatively higher contribution of GHGs and acidification at upstream production.

PE International (2014b) performed a cradle-to-grave LCA on the B-pillar of a passenger vehicle, comparing the previous press-hardened boron steel design to an advanced high strength steel (AHSS) containing molybdenum as an alloying element. The B-pillar is part of the vehicle's structural body, and its main function is to protect occupants and help maintain the structural integrity of the vehicle during a side impact. The lighter, stronger AHSS required $4 \mathrm{~kg}$ less mass than its steel counterpart to perform the same function. Results of the analysis showed that when accounting for the full life of the vehicle, lightweighting via the lower mass of the AHSS material in the B-pillar was responsible for a higher fuel efficiency during use and resulted in net overall savings for global warming potential, acidification potential, eutrophication potential, photochemical smog formation, and primary energy demand.

While the molybdenum LCIs are generally not used purely as cradle-to-gate, there are few instances where downstream life cycle stages can be rationally omitted. For example, a global flooring company used molybdenum chemical LCI data to "build" the molybdenum-bearing flame retardants in their carpet LCAs. Since the flame retardants comprise less than $2 \%$ of carpet mass and a hot spot analysis showed that they were not environmentally relevant inputs, the carpet LCA did not get into the fine detail of the flame retardants at use phase or their specific modeling at the carpet's end-of-life.

\subsection{Coproduct allocation}

Molybdenum may be mined as a single metal ore or with copper and potentially other metals in multi-metal ores. In this latter case, the copper and molybdenum coproducts need to be appropriately modeled. ${ }^{1}$ The molybdenum LCIs follow the approach recommended in PE (2014a) Table 4, i.e., for base metals, where the preferred method is to use mass allocation for the coproducts, on the basis of the total metal output. ${ }^{2}$ The choice of mass allocation is reasonable: "Mass is a consistent physical property of the metal and allows for a geographic and temporal consistency..." (PE 2014a, Table 4). Furthermore, the mass of outputs remain relatively constant over a number of years, while economic allocation (market value) could fluctuate considerably in a short period of time, leading to LCA results that may not always be representative of the system.

\footnotetext{
${ }^{1}$ See PE (2014a) or ISO (2006b) for a general discussion on handling coproducts in LCA.

${ }^{2}$ Defined informally in PE (2014a), base metals are those that have relatively low economic value, whereas precious metals have a relatively high value.
} 
For the molybdenum LCIs, the allocation percentage used was based on the mass of metals in the concentrates. ${ }^{3}$ The allocation percentage is carried upstream through to the mining process as shown in Fig. 3, to account for the actual metal recovered at the concentration process, not the potential metal found in the ore.

\subsection{Life cycle impact assessment}

The molybdenum LCIs do not include LCIA, as the intent is to enable LCA practitioners to apply impact categories that best meet the goal and scope of their studies. IMOA supports the use of the five LCIA categories recommended for use in LCAs involving metals: global warming potential, acidification potential, eutrophication potential, smog formation potential, and ozone depletion potential. These have a considerable level of scientific robustness and consensus in the LCA community. Two methodologies that could be used to calculate these and have substantial agreement among them include CML (Guinée 2002) for European-based studies and TRACI (Bare 2003) for North American studies. ${ }^{4}$

While PE (2014a) describes other categories available to LCA practitioners, including resource depletion potential, abiotic depletion potential, land use, and toxicity potential, these are less scientifically robust than those supported for molybdenum and other metals studies. PE (2014a) Sec 5.2 documents why these categories are not currently recommended for use, especially for metals LCAs. The section on human and ecological toxicity categories deserves highlighting here, as toxicity categories are so often used in LCA due to their inclusion in many popular impact methodologies (see, e.g., PE 2014a, Sec. 5.2.2.4). Furthermore, toxicity-related LCA results are often a focal point in the results - and sometimes a criterion for decision-making — since, anecdotally speaking, the perception of "toxicity" in a studied system can be emotive when it comes to the health of humans or the ecosystem. Toxicity is indeed often a necessary aspect to include when evaluating risks in a study system, but LCA is not an appropriate tool to address this. Information on fate and effects of the chemicals released to the environment are needed to understand toxicity, and since LCA does not provide this information, its use for measuring toxicity impacts is limited to the identification of potential hot spots that would require further investigation with other methods or tools such as traditional risk assessment. When toxicity assessment using LCA based toxicity impact methodologies is performed, significant caution should be exercised; results may be misleading unless limitations of the impact method and/or underlying data are clearly set forth in the interpretation stage. One example of potentially misleading toxicity results for stainless steels was featured in an early

\footnotetext{
${ }^{3}$ Ibid.

${ }^{4}$ For more discussion on this, see PE (2014a).
}

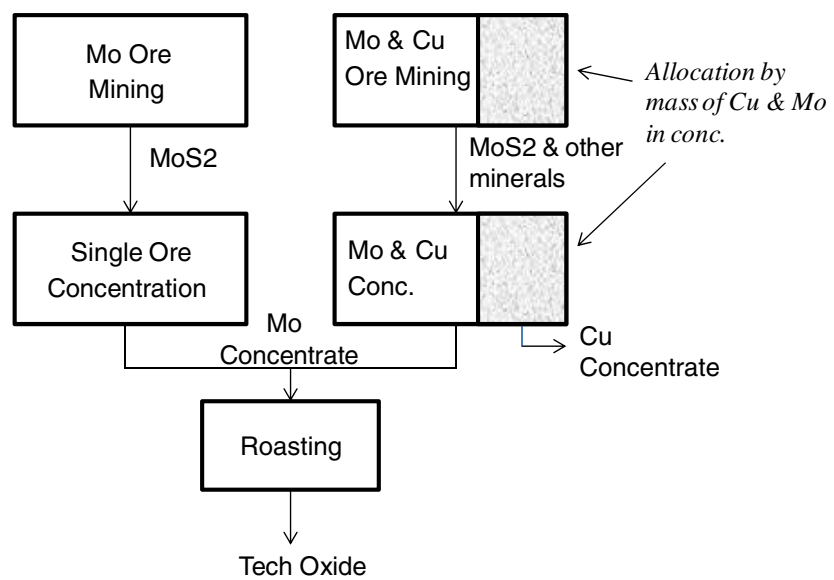

Fig. 3 Metallurgical molybdenum LCI mass allocation schematic

version of a technical report that laid the groundwork for the revision of the EU Ecolabel criteria for bed mattresses (JRC 2013). An evaluation of different metal spring materials in the spring mattress presented alarmingly high spikes in both the freshwater and marine ecotoxicity categories for the stainless steel springs (JRC 2013, Figure 14). Due to stakeholder feedback and the lack of available high quality data on stainless steel at the time, the report ultimately dismissed the analysis as inconclusive. Still, this example demonstrates the significant potential for results to be negatively misconstrued - and the merit of a material to be wrongly tarnished as a consequence - when the impact category and/or background data are not properly vetted or insufficient explanation is provided.

PE (2014a) suggests that LCA practitioners use the USEtox model (Rosenbaum 2008) if they perform toxicity assessment as part of the LCA. But even though USEtox is considered by many LCA experts to be the most robust LCA toxicity model currently available, it has significant limitations (PE 2014a, pp. 46-47 and Rosenbaum 2008). A key drawback is that the current USEtox characterization factors are within a factor of 100-1000 for human health and 10-100 for freshwater ecotoxicity (Rosenbaum 2008). Even though USEtox is considered more robust than the other toxicity modeling methods, its low level of precision should be highlighted and taken into account during the interpretation phase of the LCA.

Should toxicity assessment be performed in an LCA study, IMOA advocates the approach given in PE (2014a) Sec. 5.2.2.4: "(a) look for existing risk assessments for the metals; (b) use the current LCA toxicity models with caution; (c) make sure the most recent data/models are being used; and, (d) consider toxicity separately from other environmental indicators."

\subsection{Recycling}

MOA supports taking the recycling approach described in PE (2014a) sec. 4 when the molybdenum in molybdenum- 
bearing products is recovered and recycled into other applications, i.e., as an alloy in a new steel product.

\section{Conclusions}

Having taken part in the industry-wide LCA harmonization effort, IMOA has been able to identify and understand LCA methodology-related challenges it shares with other metals organizations. The harmonization effort has enabled the metal industry members to become aligned on many of these topics, which is beneficial given the many inherent commonalities among the metals and the hundreds of LCAs relying on these data. IMOA can educate its member companies and stakeholders about some of the challenging issues encountered in LCA, and will continue to lead through active industry participation.

IMOA's forward plan for the LCA program is to keep its LCI data current, taking into account more recent technological advances and potentially broadening the geographical coverage and number of participating IMOA members. They will continue to enhance the LCA methodology as it evolves and stay active with the other metals organizations on this subject.

While the intent is to eventually publish the LCI results in public databases such as the European Reference Life Cycle Database (ELCD) and the US LCI database, the current source of IMOA's data is via its website LCI Data Request process (IMOA 2015). This process fosters open dialogue with stakeholders and LCA practitioners, while providing IMOA with insights into how its products fit into the broader life cycle context and facilitating stakeholders' awareness of the latest issues around LCA and metals.

Open Access This article is distributed under the terms of the Creative Commons Attribution 4.0 International License (http:// creativecommons.org/licenses/by/4.0/), which permits unrestricted use, distribution, and reproduction in any medium, provided you give appropriate credit to the original author(s) and the source, provide a link to the Creative Commons license, and indicate if changes were made.

\section{References}

Bare JC, Norris GA, Pennington DW, McKone T (2003) TRACI: the tool for the reduction and assessment of chemical and other environmental impacts. J Ind Ecol http://mitpress.mit.edu/journals/pdf/jiec_6_3_49_0.pdf

First Environment, Life Cycle Inventory of Molybdenum Chemicals: Executive Summary (2006). Found at: http://www.imoa.info/ download files/HSE/LCI/MoChem_LCI_ExecutiveSummary.pdf

Four Elements Consulting, LLC, Life Cycle Inventory of Molybdenum Products: Executive Summary (2008) Found at: http://www.imoa. info/download_files/HSE/LCI/Metallurgical_Mo_LCI_ ExecutiveSummary.pdf

Guinée JB, Gorrée M, Heijungs R, Huppes G, Kleijn R, Koning A de, Oers L van, Wegener Sleeswijk A, Suh S, Udo de Haes HA, Bruijn H de, Duin R van, Huijbregts MAJ (2002) Handbook on life cycle assessment. Operational guide to the ISO standards. Part III: Scientific background. Kluwer Academic Publishers, ISBN 14020-0228-9, Dordrecht, 692 pp

International Molybdenum Association (IMOA) website (2015) http:// www.imoa.info/HSE/LCI/onlineform/online_form.php. International Stainless Steel Forum (ISSF), Stainless steel and CO2: Facts and scientific observations (2010). Found at: http://www. worldstainless.org/Files/issf/non-image-files/PDF/ISSF_Stainless_ steel and CO2.pdf

International Stainless Steel Forum (ISSF) website (2015): http:// worldstainless.org

International Standardization Organization (ISO) 14040:2006 (2006a) Environmental management. Life cycle assessment. Principles and framework

ISO 14044:2006 (2006b) Environmental management—Life cycle assessment - Requirements and guidelines

JRC-IPTS (Institute for Prospective Technological Studies) and Oakdene Hollins (2013) Draft Background Report and Proposal for Criteria Revision-Updated Working Document for the Revision of the EU Ecolabel Criteria for Bed Mattresses, Version 3. Found at: http:// susproc.jrc.ec.europa.eu/mattresses/docs/Preliminary_Report_BM_ v3.4 30012013.pdf

Lavery NP, Brown SGR, Adkins NJ, Wilson BP (2013) Life cycle assessment of sponge nickel produced by gas atomisation for use in industrial hydrogenation catalysis applications. Int J Life Cycle Assess 18(2):362-376

PE International (2014a) Harmonization of LCA methodologies for Metals, v. 1.01, February 2014

PE International (2014b) Benefits of Molybdenum Use: Ford Fusion BPillar. Found at: http://www.imoa.info/sustainability/LCA-studies.php

Rosenbaum (2008) USEtox - the UNEP-SETAC toxicity model: recommended characterisation factors for human toxicity and freshwater ecotoxicity in life cycle impact assessment. Int J Life Cycle Assess 13:532-546

worldsteel website (2015): http://www.worldsteel.org/ 